\title{
A Educação Ambiental como práxis educativa: um estudo na Escola de Ensino Fundamental Joaquim Caetano da Silva na cidade de Jaguarão/RS
}

\author{
La Educación Ambiental como praxis educativa: un estudio en la Escola \\ Estadual de Ensino Fundamental Joaquim Caetano da Silva en la ciudad \\ de Jaguarão/RS
}

The Environmental Education as educative praxis: a study in Escola Estadual de Ensino Fundamental Joaquim Caetano da Silva, in the city of Jaguarão/RS

\author{
Regiane Vieira Gonzalez ${ }^{1}$ \\ Jefferson Marçal da Rocha ${ }^{2}$
}

\begin{abstract}
Resumo
Este projeto surgiu da necessidade de discutir a concepção da Educação Ambiental como práxis educativa na Escola Estadual Joaquim Caetano da Silva, pois se percebe que a problemática ambiental está ganhando cada vez mais espaço no contexto social e político contemporâneo. O objetivo é, a partir da discussão com a comunidade escolar, provocar pequenas mudanças nos hábitos alimentares de todos os envolvidos (docentes, estudantes, funcionários, pais, familiares, etc.), valorizando, a partir da implantação de uma horta escolar, a alimentação saudável, especialmente pelo consumo de alimentos orgânicos.
\end{abstract}

Palavras-Chave: Alimentos orgânicos; Alimentação saudável; Educação ambiental.

\section{Resumen}

Este proyecto surgió de la necesidad de discutir la concepción de la Educación Ambiental como praxis educativa en la Escola Estadual Joaquim Caetano da Silva, pues se percibe que la problemática ambiental está ganando cada vez más espacio en el contexto social y político contemporáneo. El objetivo es, a partir de la discusión con la comunidad escolar, provocar pequeñas mudanzas en los hábitos alimentares de todos los involucrados (docentes, estudiantes, funcionarios, padres, familiares etc.) valorando, a partir de la implementación de una huerta escolar, la alimentación saludable, especialmente por el consumo de alimentos orgánicos.

Palabras claves: Alimentos orgánicos; Alimentación saludable; Educación ambiental.

\section{Abstract}

This project arose from the necessity to discuss about the conception of Environmental Education as educative praxis in Escola Estadual Joaquim Caetano da Silva because it is possible to notice that the Environmental issue

\footnotetext{
${ }^{1}$ (Mestranda em Educação; Universidade Federal do Pampa; Jaguarão, Rio Grande do Sul, Brasil; regiane.gonzalez07@gmail.com).

${ }^{2}$ (Professor do Programa de Pós Graduação em Educação; Universidade Federal do Pampa; São Gabriel, Rio Grande do Sul, Brasil; jeffersonrocha@unipampa.edu.br).
} 
is increasingly present in the social and political contemporary context. The purpose is, from discussion with the scholar community, to motivate little changes in eating habits of people involved (teachers, students, employees, parents, relatives, etc.) valuing, from the implantation of a school vegetable garden, especially by the consume of organic food.

Keywords: Organic food; Health eating; Environmental education.

\section{Introdução}

O Este artigo relata as perspectivas de um projeto de intervenção sobre Educação ambiental na Escola Estadual Joaquim Caetano da Silva, localizada na cidade de JaguarãoRS, a qual a primeira autora atua como docente. Percebeu-se que a Educação Ambiental está ganhando cada vez mais espaço na vida social e política contemporânea, e que as pessoas a cada dia procuram uma melhoria na qualidade de vida, diminuindo-se o consumismo, sem desperdício e tentando evitar a degradação do meio ambiente.

A intenção é que através do incentivo a implantação de uma horta escolar, seja possível potencializar ações sobre meio ambiente de forma democrática e participativa nas quais toda a comunidade escolar possa se envolver. Por meio do diálogo, desejo fomentar iniciativas voltadas para a sustentabilidade socioambiental e a melhoria da qualidade de vida no ambiente escolar em que estou inserida. A Horta Escolar, que irei propor como motivação, é uma forma de envolver a Educação Ambiental de maneira prática, um laboratório vivo, bem como utilizar a horta escolar a fim de que ocorra uma modificação de hábitos alimentares, onde seja valorizada a produção de alimentos orgânicos, que são importantíssimos para a saúde. Por meio do diálogo, deseja-se fomentar iniciativas voltadas para a sustentabilidade socioambiental e a melhoria da qualidade de vida no ambiente escolar da escola referida.

Com este projeto de intervenção viso promover mudanças de hábitos alimentares, valores e atitudes, utilizando a participação da comunidade escolar (equipe diretiva, professores, funcionários, alunos, pais e familiares) da Escola Estadual de Ensino Fundamental Joaquim Caetano da Silva. Percebe-se que deverá se criar um ambiente favorável para envolver todos os professores de todas as disciplinas, bem como os funcionários e toda a comunidade escolar para que esse projeto aconteça.

\section{Motivações}

O presente projeto nasce da necessidade de trabalhar a Educação Ambiental, na Escola Joaquim Caetano da Silva, sendo reforçada pela criação da Comissão de Meio Ambiente e Qualidade de vida (Com-Vida), que envolve escolas de Ensino Fundamental e Médio, com o principal objetivo de criar um espaço democrático e participativo que envolva toda a 
comunidade escolar em iniciativas voltadas à sustentabilidade e qualidade de vida. A partir dessa comissão poderei abordar a Educação Ambiental, já que percebo a dificuldade de trabalhar essa temática no dia- a- dia da sala de aula.

A necessidade na mudança de hábitos alimentares, através de alimentos orgânicos como hortaliças, temperos e demais alimentos nutritivos, retirados da horta da escola por alunos e professores, também é outra motivação, porque acredito que fará a diferença no contexto no qual estou inserida, pois serão criadas novas atitudes, um novo olhar com relação ao que é nosso, ao que produzimos com nosso trabalho, além de incentivar a comunidade escolar a cultivar produtos orgânicos em sua própria casa. Pois uma alimentação que contemple "[...] desde o momento do nascimento, o desenvolvimento orgânico do homem, e na verdade uma grande parte de seu ser biológico enquanto tal está submetido a uma contínua interferência socialmente determinada" (BERGER, 2010 p. 69).

Atividades na horta escolar, a partir do tema Educação Ambiental são um novo fazer pedagógico, de forma curricular emancipatória, educação para a cidadania, na qual somos sujeitos em desenvolvimento de nosso saber pedagógico, cheio de indagações e concepções que nos permitem refletir, pois, segundo Bachelard, "para o espírito científico, todo conhecimento é resposta a uma pergunta. Se não há pergunta, não pode haver conhecimento científico. Nada é evidente. Nada é gratuito. Tudo é construído" (1996, p. 18).

Hábitos alimentares saudáveis são necessários para o bom funcionamento do organismo. Uma alimentação que contemple os vegetais é importantíssima, já que hoje em dia as crianças estão totalmente habituadas aos alimentos industrializados. Plantar nem que seja uma mínima quantidade de alimento por mais simples que seja, como um tempero, uma hortaliça, uma fruta, faz toda a diferença, porque é um alimento orgânico, sem uso de agrotóxicos que causam tantos males à saúde. Para Azevedo:

[...] a agricultura orgânica tem como objetivos a autossustentação da propriedade agrícola no tempo e no espaço, a maximização dos benefícios sociais para o agricultor, a minimização da dependência de energias não renováveis na produção, a oferta de produtos saudáveis e de elevado valor nutricional, isentos de qualquer tipo de contaminantes que ponham em risco a saúde do consumidor, do agricultor e do meio ambiente, o respeito à integridade cultural dos agricultores e a preservação da saúde ambiental e humana (2012, p.113).

\subsection{Contexto da pesquisa}

O Projeto de intervenção será realizado na Escola Estadual de Ensino Fundamental Joaquim Caetano da Silva, localizada centralmente na Avenida 27 de Janeiro, n 993 no município de Jaguarão RS, é uma escola centenária, a mais antiga da cidade, com 102 anos, 
possui uma das melhores estruturas do município, apesar de ser um prédio antigo, tem como público alvo alunos do $1^{\circ}$ ao $9^{\circ}$ ano do Ensino Fundamental, com atendimento pela manhã e tarde. Possui 407 alunos (dos quais 105 possuem bolsa família), 22 professores (na qual 15 possuem formação de atuação na área), uma diretora, 2 vice-diretoras, 1 orientadora educacional, 1 agente educacional, 1 supervisora, 3 funcionárias da cozinha e 3 funcionários da limpeza.

A escola sofreu reformas, em algumas salas de aula, como forro, piso, pintura e manutenção de vidros. Possuem 09 salas de aula, uma biblioteca, uma sala de professores, uma sala de orientação, uma sala de supervisão, uma sala de direção, uma secretaria, uma sala de jogos para educação física, quatro banheiros (masculino e feminino) sendo dois noandar de cima e dois no andar de baixo. No pátio tem mais 3 salas de aula, a cozinha, o refeitório e uma pequena peça de manutenção.

\section{Objetivo Geral:}

Este projeto de intervenção tem como objetivo geral: Promover a Educação Ambiental e a discussão da alimentação saudável, através da horta escolar na Escola Estadual de Ensino Fundamental Joaquim Caetano da Silva.

\section{Objetivos específicos:}

a) Estabelecer discussões sobre os hábitos alimentares nos alunos, professores, funcionários e toda a comunidade acadêmica da Escola Estadual de Ensino Fundamental Joaquim Caetano da Silva, através da implantação da horta escolar;

b) Identificar a horta escolar, como um espaço de aprendizagem, um laboratório vivo para adquirir conhecimentos sobre Educação Ambiental;

c) Discutir a diferença entre soberania alimentar de segurança alimentar;

d) Reconhecer os princípios ambientais, a partir de alimentos orgânicos;

\section{Justificativa:}

Justifica-se esta pesquisa pela importância de que a Educação Ambiental seja discutida por toda a comunidade escolar, percebo na Escola Joaquim Caetano da Silva que existe poucas discussões sobre o assunto.

Salienta-se também que este projeto de intervenção surgiu de um e-mail da $5^{\circ} \mathrm{CRE}$ Pelotas, em 05/05/2004, orientando a escola para a criação da Comissão de Meio Ambiente na Escola Joaquim Caetano da Silva, através do Prof. Vanderley Pimentel da Assessoria de 
Educação Ambiental, neste mesmo e-mail havia pedido urgente de professor para formação em Educação Ambiental/ Afro e Quilombola, deixando claro que fosse um professor que já tivesse participado das formações anteriores em Educação Ambiental. Esta ação veio a calhar com a proposta que pretendia desenvolver no programa de Mestrado profissional em Educação da Unipampa, pois através da criação da Comissão de Meio Ambiente na Escola Joaquim Caetano da Silva, fui convidada pela equipe diretiva da escola para participar como membro dessa comissão.

A Educação ambiental procura trabalhar noções como cidadania, sustentabilidade, justiça social, apoiada no diálogo, na conscientização, como diz Loureiro:“[...]no fortalecimento dos sujeitos, na superação das formas de dominação capitalistas e na compreensão do mundo em sua complexidade e da vida em sua totalidade" (2009, p.24).

A Comissão de Meio Ambiente e Qualidade de Vida (COM-VIDA), tem por objetivo desenvolver projetos que visem tornar as escolas sustentáveis. Reigota argumenta o seguinte:

A educação visando ao desenvolvimento sustentado se fundamenta principalmente nos aspectos sócio- éticos e não nos produtivos e econômicos, sendo que estes dois últimos são subordinados aos dois primeiros (2001, p. 45).

A COM-VIDA pretende potencializar ações de Educação ambiental ( $6^{\circ}$ e $9^{\circ}$ anos) e ensino médio, através de um espaço democrático e participativo na qual abranja toda a comunidade escolar, criando iniciativas de sustentabilidade a fim de possibilitar uma melhoria da qualidade de vida da escola e da sua comunidade, bem como promover o diálogo sobre temas socioambientais contemporâneos. Sendo, assim, surgiu a necessidade de criar essa comissão de Meio Ambiente, em nossa escola, para debatermos assuntos sobre sustentabilidade e conservação de recursos naturais.

Acredita-se que a horta escolar é muito importante de ser trabalhada e discutida na Educação ambiental, por promover a possibilidade de um maior contato dos alunos com a natureza e sem falar da necessidade de mudança de hábitos alimentares desde cedo, através de hortaliças, temperos e demais alimentos nutritivos, retirados da horta escolar por alunos e professores que acredito fazer toda a diferença, pois cria novas atitudes, um novo olhar com relação ao que é nosso, ao que produzimos com nosso trabalho e dedicação.

A Escola Joaquim Caetano da Silva se organiza para formar sua própria Comissão de Meio Ambiente, através da Professora Ivolete, supervisora escolar e são organizadas algumas reuniões para sanar dúvidas e dar orientações. Sendo assim, fui incentivada a trabalhar a temática Educação Ambiental, com a principal motivação a horta escolar através da formação 
da comissão do Meio Ambiente e Qualidade de Vida na Escola Joaquim Caetano da Silva, na qual faço parte. Tivemos algumas reuniões, onde uma delas teve a participação da equipe da EMATER, como forma de parceria, para dar orientações e suporte para a construção da horta escolar.

Em função da Comissão de Meio Ambiente da Escola Estadual de Ensino Fundamental Joaquim Caetano da Silva, existe a Horta Escolar, onde os alunos trabalham plantando árvores frutíferas, ervas medicinais, temperos e hortaliças. O projeto da horta já foi encaminhado para a $5^{\circ} \mathrm{CRE}$ e foi homologado.

A Educação Ambiental através da construção de valores e atitudes voltados à vida, a preservação do ambiente, envolve metodologias interdisciplinares, capazes de fazer o aluno refletir, dialogar e sobre tudo transformar sua realidade. Como diz Guimarães, "ser capaz de contribuir com a transformação de uma realidade que historicamente se coloca em uma grave crise socioambiental" (2004, p.25).

Concluo que a Comissão de Meio Ambiente tem uma grande importância no ambiente escolar, pois cria uma visão planetária, emancipatória, reflexiva e crítica, estabelecendo experiências enriquecedoras de aprendizagem.

Justifica-se também o Projeto de intervenção através do Projeto Político Pedagógico da Escola, que menciona a escola sustentável, abordando a Educação Ambiental em todos os anos de ensino, envolvendo todas as disciplinas e o currículo.

O que existe na escola é um Projeto de coleta de papel, para a reciclagem, na qual cada aula possui uma lixeira para os demais produtos e uma lixeira confeccionada de papelão para colocar o papel que será descartado pelos alunos, e logo após será doado para a reciclagem, ou seja, um trabalho mais abrangente na verdade não existe. O Projeto Político pedagógico é uma tarefa da escola, é uma prática educativa, porque é um processo que se constrói constantemente, sendo assim, é assumir a educação como um processo de ensino aprendizagem onde preponderam convicções, valores, etc. a participação de todos (professores) em especial, equipe diretiva, comunidade escolar é necessário para que ocorra a democratização do sistema de ensino.

Observei também a Matriz Curricular anos Iniciais e finais da Escola Joaquim Caetano da Silva e conclui que somente algumas disciplinas como Ciências, Geografia e Espanhol contemplam a temática Ambiental, já as outras disciplinas nenhum conteúdo faz referência. Consta uma observação que durante o ano letivo serão desenvolvidos trabalhos sobre CulturaAfro e Meio Ambiente, mas não diz quais trabalhos e como serão desenvolvidos. 
A Educação Ambiental é um processo permanente, onde os indivíduos adquirem conhecimentos, habilidades, valores que os tornam capazes de solucionar problemas ambientais para as presentes e as futuras gerações. A Educação Ambiental incorpora várias dimensões como sociais, políticas, econômicas, culturais, ecológicas e éticas.

Durante a Rio-92, que é a Conferência das Nações Unidas sobre Meio Ambiente e desenvolvimento (Cnumad), que foi realizada em junho de 1992 no Rio de Janeiro que através das organizações não governamentais, formularam o trabalho de Educação Ambiental para Sociedades Sustentáveis e Responsabilidade Global onde se estabelece alguns princípios, dos quais irei citar um deles: “A Educação Ambiental deve integrar conhecimentos, aptidões, valores, atitudes e ações, convertendo cada oportunidade em experiências educativas de sociedades sustentáveis" (Fórum Global da Rio-92).

Com isso, fica claro que a Educação Ambiental, tem por objetivo a conscientização ambiental, através da adoção de comportamentos ecológicos corretos, colocados em prática pelos cidadãos. Sendo assim, é importante estratégias, para a construção do processo de cidadania e da qualidade de vida das pessoas. E a escola torna-se uma aliada importante, ao incorporar essas atitudes e valores, que despertem um olhar especial para perceber que os recursos naturais são finitos, e o consumismo exagerado só dificultará viver com qualidade.

A educação ambiental é o meio reflexivo, crítico e autocrítico contínuo, pelo qual podemos romper com a barbárie de padrão vigente de sociedade e de civilização, em um processo que parte do contexto, estabelecendo societário em que nos movimentamos do "lugar" ocupado pelo sujeito, estabelecendo experiências formativas, escolares ou não, em que a reflexão problematizadora da totalidade, apoiada numa ação consciente e política, propiciam a construção de sua dinâmica (LOUREIRO, 2009, p. 32).

A Educação Ambiental deve ser transformadora, pois é fundamental para estabelecer uma ligação mais íntima entre o homem e a natureza. É necessário motivar toda a comunidade escolar para uma alimentação saudável, utilizando a horta escolar como uma ferramenta de aprendizagem. Sendo, assim, espero modificar o modo de pensar dos professores, alunos, pais e familiares, ou seja, toda a comunidade escolar.

Essa transformação social entende-se, conforme Sorrentino (2005), como a superação das injustiças ambientais e sociais da humanidade. O professor deve preocupar-se não somente em passar conteúdos programáticos, mas deve estar alicerçado na criatividade, na curiosidade, na mudança de valores e atitudes e estimular em seus alunos essa capacidade de tornar-se crítico e reflexivo, mesmo tendo um ensino bancário. 
O necessário é que, subordinado, embora a prática" bancaria", o educando mantenha vivo em si o gosto da rebeldia que, aguçando sua criatividade e estimulando sua capacidade de arriscar-se, de aventurar-se de certa forma o " imuniza" contra o poder apassivador do bancarismo (FREIRE, 1996, p.25).

Eu me vejo refletindo todos os dias sobre minha prática docente como professora das séries finais do Ensino Fundamental e do Ensino Médio, surgem várias inquietações, medo e angústia. Através de leituras tento achar as respostas para decifrar tantas perguntas. Eu percebo que tenho todos os dias que rever minha prática como professora de escola pública, afinal,

[...] na formação permanente dos professores, o momento fundamental é o da reflexão crítica sobre a prática. É pensando criticamente a prática de hoje ou de ontem que se pode melhorar a próxima prática (FREIRE, 1996, p. 39).

Rever conceitos que contribuam para a formação de opinião própria sobre a problemática ambiental é essencial para estabelecer uma relação saudável frente a natureza, isso faz parte da essência do homem. Segundo Roessler, "todo homem civilizado deve admitir obrigações de impedir devastações e selvagerias; sua empatia e seu amor pela flora e fauna são as últimas qualidades morais adquiridas pela educação" (2005. p.87).

De acordo com os Parâmetros Curriculares Nacionais (1998), a Educação Ambiental deve estar interligada com todas as disciplinas de um currículo e com a Lei $n^{\circ} 9.795$ a Educação Ambiental deve estar presente em todos os níveis da educação formal, pois é uma necessidade nos dias de hoje, por abordar a sustentabilidade, a qualidade de vida no espaço de formação, ou seja, na escola na qual atuo. A colaboração de todos (equipe diretiva, professores, alunos, funcionários, pais e familiares), multiplicadores de boas atitudes, cada qual com sua disciplina trabalhando o mesmo tema de forma interdisciplinar, em busca da compreensão e da resolução de problemas.

A temática a ser trabalhada será a contribuição da Educação Ambiental de forma interdisciplinar, através da construção da Horta Escolar na Escola Joaquim Caetano da Silva, já que com esse tema, surge um leque de opções a ser trabalhada, através de conceitos e atitudes voltadas para a preservação do ambiente, a importância da Educação Ambiental, a consciência da responsabilidade de que todos somos parte da natureza e a construção de valores mais humanos que devem permear o processo educativo, tendo em vista a relação saudável desde cedo com o meio ambiente. 
Percebo que a horta escolar é uma ferramenta pedagógica importantíssima para aprender de forma lúdica, ou seja, os conteúdos trabalhados de forma interdisciplinar desde as séries iniciais até as séries finais, num contexto integrador entre professor e aluno, contribuindo assim para uma educação de qualidade, de sustentabilidade e de emancipação.

O trabalho com a horta (plantio de sementes, cultivo, cuidados) tudo isso se torna uma fonte imensa de aprendizagem, pois os alunos vão adquirindo pequenas mudanças nos hábitos que fazem toda a diferença no seu dia a dia, adquirindo com isso, hábitos saudáveis que perpetuarão também fora da escola. Com esse projeto, também percebo a valorização e o respeito pelo meio ambiente, utilizando o reaproveitamento de materiais recicláveis como garrafas pet, o conhecimento sobre compostagem, cultivo de temperos, morangos, hortaliças e o consumo de alimentos colhidos na horta entre outras atividades que favorecerão o processo educativo.

\subsection{Diagnóstico prévio no contexto escolar}

A Como diagnóstico foram realizados questionários com alunos sobre o uso de alimentos saudáveis e não saudáveis. O diagnóstico apresentado justifica a intervenção, pois percebe-se que os alunos costumam consumir frutas, legumes e verduras em sua alimentação, porém alguns demonstraram resistência ao consumo de vegetais. Foi realizado questionário com as seguintes turmas: $6^{\circ}$ ano, 61 (com 24 alunos presentes) e 62 (34 alunos presentes) e $7^{\circ}$ ano, turma 71 (27 alunos) e 72 (30 alunos presentes).

1) Você gosta de vegetais?

\begin{tabular}{|l|l|l|}
\hline TURMAS & SIM & NÃO \\
\hline $6^{\circ} 61$ & 17 & 07 \\
\hline $6^{\circ} 62$ & 21 & 09 \\
\hline $7^{\circ} 71$ & 20 & 07 \\
\hline $7^{\circ} 72$ & 27 & 03 \\
\hline Total & 85 & 26 \\
\hline
\end{tabular}

2) Você gosta de consumir frutas?

\begin{tabular}{|l|l|l|}
\hline TURMAS & SIM & NÃO \\
\hline
\end{tabular}




\begin{tabular}{|l|l|l|}
\hline $6^{\circ} 61$ & 24 & 07 \\
\hline $6^{\circ} 62$ & 30 & 09 \\
\hline $7^{\circ} 71$ & 23 & 07 \\
\hline $7^{\circ} 72$ & 29 & 03 \\
\hline Total & 106 & 26 \\
\hline
\end{tabular}

3) Com qual frequência utiliza os vegetais?

\begin{tabular}{|l|l|l|l|}
\hline Turmas & Diariamente & semanalmente & Não utilizo \\
\hline $6^{\circ} 61$ & 04 & 20 & 0 \\
\hline $6^{\circ} 62$ & 02 & 26 & 01 \\
\hline $7^{\circ} 71$ & 06 & 19 & 01 \\
\hline $7^{\circ} 72$ & Ninguém & 25 & 02 \\
\hline Total & 12 & 90 & 04 \\
\hline
\end{tabular}

4) Com qual frequência utiliza as frutas?

\begin{tabular}{|l|l|l|l|}
\hline Turmas & Diariamente & semanalmente & Não utilizo \\
\hline $6^{\circ} 61$ & 11 & 13 & 0 \\
\hline $6^{\circ} 62$ & 02 & 31 & 01 \\
\hline $7^{\circ} 71$ & 06 & 19 & 02 \\
\hline $7^{\circ} 72$ & 12 & 25 & 01 \\
\hline Total & 31 & 88 & 04 \\
\hline
\end{tabular}

5) Quais são os seus vegetais preferidos? Os mais citados por todas as turmas questionadas, foram os seguintes: alface, couve, beterraba, abobora, cenoura e repolho.

6) Quais são suas frutas preferidas? As mais citadas pelas turmas foram as seguintes: maça, banana, bergamota, abacaxi, melancia, morango, pêssego, uva, manga, abacate e pera.

7) Com qual frequência costuma consumir salgadinho, refrigerante e doce?

\begin{tabular}{|l|l|l|l|}
\hline Turmas & Diariamente & Semanalmente & Não utilizo \\
\hline
\end{tabular}




\begin{tabular}{|l|l|l|l|}
\hline $6^{\circ} 61$ & 01 & 22 & 01 \\
\hline $6^{\circ} 62$ & 12 & 22 & 0 \\
\hline $7^{\circ} 71$ & 09 & 18 & 0 \\
\hline $7^{\circ} 72$ & 03 & 26 & 01 \\
\hline Total & 25 & 88 & 02 \\
\hline
\end{tabular}

A partir deste diagnóstico prévio percebi que a proposta de se construir uma horta escolar envolvendo toda a comunidade da escola seria uma alternativa importante para debater a problemática interdisciplinar com temas como: educação ambiental, alimentação saudável, soberania alimentar, entre outros que por ventura virão a surgir na intervenção prevista, favorecendo assim, a aprendizagem de toda a comunidade escolar.

\section{Procedimentos Metodológicos da Intervenção}

O estudo proposto aqui será uma pesquisa-ação a ser realizado na Escola Estadual de Ensino Fundamental Joaquim Caetano da Silva no município de Jaguarão, onde será tratado o tema Educação Ambiental. Através da proposta de implantação de uma Horta Escolar Comunitária que procurará abranger toda a comunidade escolar, desde alunos $\left(1^{\circ}\right.$ ao $9^{\circ}$ ano), passando pelos professores, pela equipe diretiva, pelos funcionários e culminando com os familiares dos alunos da referida escola.

A metodologia escolhida baseia-se na pesquisa-ação, que é um tipo de pesquisa social com base empírica que é concebida e realizada em estreita associação com uma ação ou com a resolução de um problema coletivo e no qual os pesquisadores e os participantes representativos da situação ou do problema estão envolvidos de modo cooperativo e ou participativo (THIOLLENT, 2009, p.16). Terá uma abordagem qualitativa, pois "os métodos qualitativos enfatizam as particularidades de um fenômeno em termos de seu significado para o grupo pesquisado. É como um mergulho em profundidade dentro de um grupo "bom para pensar" questões relevantes para o tema estudado" (GOLDENBERG, 2004, p. 50).

Será realizado um diagnóstico inicial sobre a problemática proposta (parte deste diagnóstico serviu para elaborar este projeto) e após será proposta a construção de uma horta escolar na escola. Será utilizada também uma exposição fotográfica com todas as atividades realizadas referente à horta escolar. 
A intenção é que as participações dos segmentos escolares sejam de forma efetiva e dialógica, contribuindo, assim, para uma aprendizagem mútua em que o aluno seja o principal agente deste processo. Para Reigota,

\begin{abstract}
pensar em uma mudança radical da sociedade,tem como base uma perspectiva ecológica, é uma utopia que não deve ser entendida como ingênua ou impossível, mas como um conjunto de idéias (sic) que tendem a gerar atividades visando mudanças no sistema prevalecente (2001, p. 22).
\end{abstract}

Abrangerá toda a comunidade escolar da Escola Joaquim Caetano da Silva, 22 professores, 3 funcionários da limpeza e 3 funcionárias da cozinha, equipe diretiva (uma diretora, 2 vice- diretoras), 1 orientadora educacional, 1 agente educacional, aproximadamente 60 alunos das séries iniciais ( $1^{\circ}$ ao $5^{\circ}$ ano), cerca de 150 alunos das séries finais ( $6^{\circ}$ ano ao $9^{\circ}$ ano), e familiares dos envolvidos. Sendo que os alunos do $6^{\circ}$ e $7^{\circ}$ anos serão os orientadores dos colegas do turno da tarde.

A intervenção terá uma abordagem qualitativa. Para Minayo (2003, p. 16-18), é o caminho do pensamento a ser seguido. Ocupa um lugar central na teoria e trata-se basicamente do conjunto de técnica a ser adotado para construir uma realidade.

Toda a comunidade escolar ficará encarregada pela doação, preparação e manutenção de canteiros, almácegos, transplante de mudas, irrigação (como utilizar a água para a rega de maneira sustentável), limpeza, manutenção, cuidados que se deve ter para evitar o ataque de pragas, sendo assim, cada turma ficará encarregada de uma determinada atividade em relação à horta, durante todo o ano letivo.

Professores e funcionários também poderão ter um pequeno canteiro onde plantarão hortaliças de sua preferência. Tentarei motivá-los para participar da horta com a seguinte pergunta. Quer ter um cantinho da horta só para você? Tentar incentivá-los a plantar algo de seu interesse, na horta escolar e ficar encarregado pelos cuidados.

As atividades interdisciplinares com os professores ocorrerão durante uma semana com o tema Horta Escolar: Mudança de hábitos alimentares, com o título: $1^{\circ}$ Semana Interdisciplinar na Escola Joaquim Caetano da Silva. Cada professor trabalhará em sua disciplina alguma atividade. Os professores de Português poderão trabalhar redações, poesias e uma ótima sugestão para trabalhar a ortografia é a música "Primavera" de Vivaldi. Arte poderá trabalhar pintura em quadros relacionados ao tema em questão. Outras sugestões de atividades para as demais disciplinas serão entregues aos professores em reunião. Também 
será utilizado questionário com os professores relatando o que foi trabalhado em suas aulas durante a semana.

A educação ambiental segundo Dias (1994) se caracteriza por incorporar as dimensões sociais, políticas, econômicas, culturais, ecológicas e éticas, o que significa que ao tratar de qualquer problema ambiental, deve-se considerar todas as suas dimensões.

\section{Resultados esperados}

A educação nesta perspectiva procura refletir as relações do ser humano, com as outras formas de vida existente, viver de forma digna, para o bem comum é uma forma de praticar a educação, nós seres humanos que criamos problemas para a natureza, devemos achar as soluções para amenizá-los.

Art. $4^{\circ}$ São princípios básicos da Educação Ambiental.

- Enfoque humanístico, holístico, democrático e participativo;

- Concepção de Meio Ambiente em sua totalidade, considerando a interdependência entre o meio natural, o socioeconômico e o cultural, sob o enfoque da sustentabilidade;

- O pluralismo de idéias e concepções pedagógicas, na perspectiva da inter, multi e transdisciplinaridade;

- A vinculação entre a ética, a educação, o trabalho e as práticas sociais;

- A garantia de continuidade e permanência do processo educativo;

- A abordagem articulada das questões ambientais locais, regionais, nacionais e globais;

- O reconhecimento e respeito à pluralidade e à diversidade individual e cultural. Lei n 9.795 de 27 de abril de 1999.

Espera-se que através das atividades a serem desenvolvidas na Escola Estadual de Ensino Fundamental Joaquim Caetano da Silva, os alunos substituam atitudes e valores antigos, por uma nova visão, mais crítica, passando para um paradigma planetário, na qual se interesse em modificar e interagir no meio em que estão inseridos. A educação ambiental cria nos alunos uma cidadania ambiental, em que valoriza a reflexão e faz com que se motivem a trabalhar na horta escolar, pois a participação dos alunos em atividades como plantio, 
cuidados e manutenção da horta é essencial para uma aprendizagem significativa, além de criar uma motivação a mais ao consumo de alimentos orgânicos, garantindo assim, uma melhor qualidade de vida.

\section{Considerações finais}

A restauração e conservação do meio ambiente é uma responsabilidade de todos, sendo assim, a adoção de ações de sustentabilidade, ou seja, o bom uso dos recursos naturais da Terra garante condições para o desenvolvimento de diversas formas de vida, inclusive o ser humano. Passar essas noções para os alunos é de suma importância, pois serão multiplicadores, fazendo a diferença no contexto social em que estão inseridos.

Considero a Educação Ambiental como uma temática importante de ser trabalhada no ambiente escolar, na medida em que passa a contribuir para o processo de transformação da sociedade atual em uma sociedade sustentável, centrando no exercício responsável da cidadania, que considere a natureza como um bem comum, leve em conta a capacidade de regeneração dos recursos materiais, promova a distribuição equitativa da riqueza gerada e favoreça condições dignas de vida para as gerações atuais e futuras (SADER, 1992).

Por fim, valorizar uma alimentação orgânica, limpa de agrotóxicos, que respeita e cuida do meio ambiente, é fundamental, pois além de ser um ganho para a saúde, não podemos esquecer que o consumo de alimentos saudáveis, como frutas e vegetais, podem interferir significativamente na vida do planeta, na sustentabilidade.

De forma resumida, pode-se dizer que os orgânicos têm maior qualidade porque são produzidos em solo com maior equilíbrio de nutrientes. Além disso, não apresentam resíduos de agrotóxicos e fertilizantes sintéticos, de hormônios e drogas veterinárias usadas na produção animal, ou aditivos químicos, vitaminas e minerais sintéticos e resíduas de substâncias radioativas resultantes do processamento de alimentos (AZEVEDO, 2012, p. 139).

Espera-se que através das atividades a serem desenvolvidas na Escola Estadual de Ensino Fundamental Joaquim Caetano da Silva, os alunos substituam atitudes e valores antigos, por uma nova visão, mais crítica, passando para um paradigma planetário, na qual se interesse em modificar e interagir no meio em que estão inseridos. A educação ambiental cria nos alunos uma cidadania ambiental, em que valoriza a reflexão e faz com que se motivem a trabalhar na horta escolar, pois a participação dos alunos em atividades como plantio, cuidados e manutenção da horta é essencial para uma aprendizagem significativa, além de 
criar uma motivação a mais ao consumo de alimentos orgânicos, garantindo assim, uma melhor qualidade de vida.

\section{Referências}

AZEVEDO, E.de. Alimentos orgânicos: ampliando os conceitos de saúde humana, ambiental e social. São Paulo: Editora Senac, 2012.

BACHELARD, G.. A formação do espírito científico. São Paulo: Contraponto/UNESP, 1996.

BARDIN, L. Análise de conteúdo. Lisboa: LDA, 2009.

BERGER, P. L; LUCKMANN, T.A Construção social da realidade. 32. ed. Traduzido por Floriano de Souza Fernandes. Petrópolis, Vozes, 2010.

BOFF, L. A carta da Terra e a consciência planetária:um olhar "de dentro". In: OLIVEIRA, P.A. R; SOUZA, J.C.A. (Orgs.).Consciência planetária e religião: desafios para o século XXI. São Paulo: Paulinas. 2009.

L. Saber cuidar: ética do humano - compaixão pela terra. Petrópolis: Vozes, 2008.

Brasil Escola - UOL (Brasil escola. uol.com. br/saúde.../o - que - são alimentos saudáveis. Disponível em:

<htmhttp://www.scielo.br/scielo.php?script=sci_arttex\&pid=S151797022005000200010\&lng $=$ pt\&nrm=isso $>$. Acesso em: 23/ 07/ 2017.

Brasil. Ministério da Educação/Ministério do Meio Ambiente. Formando Comissão de Meio Ambiente e Qualidade de Vida na Escola: Construindo Agenda 21. Brasília: Coordenação Geral de Educação Ambiental, 2004.

BRASIL. Ministério da Educação.Lei de diretrizes e bases da educação nacional.

BRASIL. Ministério da Educação. Parâmetros curriculares nacionais: Língua Portuguesa. Brasília: MEC/SEF, 1998.

CEPAL. Desarrollo rural en América Latina y el Caribe: laconstrucción de unnuevo modelo. Disponível em: <http://www.cepal.org/es/publicaciones/1661-desarrollo-ruralamerica-latina-caribe-la-construccion-un-nuevo-modelo >. Acesso em: 25 julho 2017.

DIAS, G.F. Educação ambiental: princípios e práticas. São Paulo, Gaia, 1992.

FREIRE, P. Pedagogia da autonomia: Saberes necessários à prática educativa. São Paulo: Paz e Terra, 1996.

GALLO, S. Transversalidade e meio ambiente. Ciclo de palestras sobre o meio ambiente. Brasília: MEC/ SEF, 2001. 
GHIGGI, G. A pedagogia da autoridade a serviço da liberdade: diálogos com Paulo Freire e professores em formação. Pelotas: Seiva, 2002.

GIL, A.C. Métodos e técnicas de pesquisa social. 5 ed. São Paulo: Atlas, 1999.

GOLDENBERG, Miriam. A arte de pesquisar: como fazer pesquisa qualitativa em

Ciências Sociais. ed. 8. Rio de Janeiro: Record, 2004.

GUIMARÃES, M. A educação ambiental crítica. In: LAYRARGUES, P.P. Identidades da educação ambiental brasileira. Brasília: Ministério do meio Ambiente, 2004.

LEFF, E. Epistemologia ambiental. São Paulo: Cortez, 2002.

Saber Ambiental: Sustentabilidade, Racionalidade, Complexidade, Poder. 8. ed. Petrópolis: Vozes, 2011.

LOUREIRO, C.F.B. Trajetória e fundamentos da Educação Ambiental. São Paulo: Editora Cortez, 2009.

MAGALHÃES, A. M. A horta como estratégia de educação alimentar emcreche. 2003. 120 f. Dissertação (Mestrado em Agros ecossistemas). Universidade Federal de Santa Catarina, Florianópolis, 2003.

MINAYO, M.C.de S.(Org.) Pesquisa social: teoria, método e criatividade. 22 ed. Rio de Janeiro: Vozes, 2003.

MOLINA NETO, V.; TRIVIÑOS, A. S.(Org.). A pesquisa qualitativa na Educação Física: alternativas metodológicas. Porto Alegre: EDUFRGS, 1999.

REIGOTA, M. Meio ambiente e representação social. 4. ed. São Paulo: Cortez, 2001.

O que é educação ambiental. 2. ed. São Paulo: Brasiliense, 2009.

ROCHA, J. M. da. Sustentabilidade em questão: economia, sociedade e meio ambiente.

Jundiaí:, Paco Editorial: 2011.

ROESSLER, H. L.O Rio Grande do Sul e a ecologia: crônicas escolhidas de um naturalista contemporâneo. 2. ed. Porto Alegre: Governo do Estado do Rio Grande do

Sul/SEMA/FEPAN, 2005.

SADER, E. A ecologia será política ou não será. In: GOLDENBERG, M. (Org.).Ecologia, ciência e política: participação social, interesses em jogo e luta de ideias no movimento ecológico. Rio de Janeiro: Revan, 1992. p. 135-142.

SORRENTINO, M. et al. Educação ambiental como política pública:educação e pesquisa. v. 31. n. 2. São Paulo, 2005. Disponível em:

$<$ http://www.scielo.br/scielo.php?script=sci_arttex\&pid=S151797022005000200010\&lng=pt $\& n r m=i s o>$.Acesso em: 23 julho 2017.

THIOLLENT, Michel. Metodologia da Pesquisa- Ação. São Paulo: Cortez, 1985. 
TRIVIÑOS, A. N. S. Introdução à pesquisa em Ciências Sociais: a pesquisa qualitativa em educação. São Paulo: Atlas, 1987. 